The merit of this work is that it defines the thoughts of an informed Christian regarding the problems caused by biomedical progress.

The different techniques in several medical procedures such as artificial insemination, in vitro fertilisation, contraception, abortion etc, are expressed in a clear manner.

As a Christian, emphasising the effects that these innovations will have on the society, he warns against their use without taking into account the human being, and the quality of life, one aims for.

Therefore, this book is a testimony, a testimony of a Christian whose aims and thoughts have to be considered as a contribution to a discussion on ethics. This work, which is inspired by a tradition which the author holds, cannot by itself be a reference book of medical ethics. Medical ethics are the result of a consensus and therefore cannot arise from any single sectarian attitude be it religious, political or scientific.

The procedures described dramatise the disadvantages of the use of modern techniques without demonstrating their benefits. (For example, the fictitious anecdotes reveal only excessive application.)

If society has to take a position on the use of biomedical innovation, it cannot take the risk of not accepting it. The achievement of a consensus between science, morals and politics, which can be the only way to define the ethics, will need a clarification of the motives of these parties.

So, even if this book cannot be considered as a work of medical ethics, it has to be seen as conveying the position of a thinking Christian with regard to the progress of modern medicine.

DR MARC FELLOUS Immunogenetique Humaine Institut Pasteur 28 rue de Dr Roux 75724 Paris, Cedex 15 France

\section{La Fecondazione Artificiale: Questioni Morali Nell'Esperienza Giuridica}

Maurizio Mori, 341 pages, Italy, L.28000, Giuffré, 1988
The moral dilemma of in vitro fertilization (IVF) is to decide whether or not it is permitted to intervene in the procreative sphere. In Mori's book, the author pinpoints the problem in the first pages, underlining the fact that the choice is not easy because there are two alternative understandings of life. Essentially, IVF is a kind of test case, where logical reasoning cannot eliminate all doubts. In these circumstances there is a balance of logical arguments on the two sides and consequently moral intuitions or moral sense become relevant factors in choosing what is right and what is wrong. According to Toulmin's affirmations, we can say that we are faced by a personal choice of life.

I think that this resembles the epistemological theories of $\mathrm{T}$ Khun, who affirms that scientific paradigms are not comparable (the paradigm is the group of scientific theories which, at a given moment in history, defines the perspective in which particular scientific research operates). For example, while the particular theories of the Ptolemaic System or the Copernican system can be examined rationally, the two systems as a whole are not comparable with each other, as their points of departure are different, one geocentric, and the other heliocentric. But, as in this kind of philosophy, it is not easy to explain how we can choose between two possible decisions in the balance.

What is original in Mori's proposal is the fact that he maintains that in difficult cases, logical reasoning does not guarantee the victory of either one of the contrasting theories. However, he believes that rational attempts, which may sway the balance, are possible. In this way we may avoid the rather unsatisfactory conclusion that the decisions must be made under the influence of moral intuitions and subjective moral sense.

The road which Mori indicates to us is that of moral analysis which is implicit in current law, and in particular, in Italian law. Consideration of the sentences handed down in two cases involving artificial insemination (Rome 1956 and Padua 1957) followed by a careful analysis of the subsequent debate, permits Mori to come to an interesting conclusion. In actual fact, the moral code which is implicit in current Italian legislation is not in principle against artificial insemination, because fatherhood is based primarily on social considerations and not biological links. Thus, if the biological systems do not work there are no valid objections to interventions in the procreative process, even if this changes the normal biological relationship of a couple.

Of course, in this way, we cannot automatically solve the problem about the balance between the arguments in favour and the arguments against IVF. We can, however, according to Mori, at least overcome a stalemate position and presume that it is legal to intervene medically in procreation. It is up to those who are against this view to prove their own case.

It is easy to see who Mori's principal target is: those who on behalf of the Catholic Church argue against any kind of IVF. As this position is strongly held, particularly in Italy, it is highly appropriate that a dissenting voice on the part of non-clerical bodies be raised.

RAFFAELE PRODOMO Doctor of Forensic Medicine, Via G Santacroce 15, Napoli, Italy

\section{Biomedical Ethics Reviews 1987}

\section{Edited by $\mathrm{J} M$ Humber and}

R F Almeder, 185 pages, New Jersey, USA, £32.70, Humana Press, 1988

This edited work is written for professional and lay readers in order to explore ethical issues of current importance. This, the fifth volume in an edited series contains seven chapters written by contributors from the health care and ethical disciplines. Each of the three sections, which are introduced by the editors, is quite different in style and depth of analysis. Some subjects will be more accessible to the 'untrained' reader than others.

The first, and the most discursive section, on care of the elderly or those near the end of their lives and the problems of respecting their autonomy in various situations involving medication is richly illustrated by case material. Many of these vignettes are probably relatively familiar to those with aged relatives. Difficulties in coping with chronically deteriorating abilities in the elderly and the effects on others may influence practitioners to prescribe for the benefit of carers rather than the patient, whose own wishes are either not explored fully or excluded in the cause of safety. The problem of deciding whether to treat those elderly who are very disabled is also aired and this section concludes with a list of rules for prescribing. It serves as a clear 